\title{
Effect of Video-Cases on the Acquisition of Situated Knowledge of Teachers
}

\author{
Walter M. Geerts ${ }^{1}$, Henderien W. Steenbeek ${ }^{2} \&$ Paul L. C. van Geert ${ }^{2}$ \\ ${ }^{1}$ Department of Teacher Education, NHL University of Applied Sciences, Leeuwarden, The Netherlands \\ ${ }^{2}$ Department of Developmental Psychology, University of Groningen, Groningen, The Netherlands \\ Correspondence: Walter M. Geerts, Department of Teacher Education, NHL University of Applied Sciences, \\ Leeuwarden, The Netherlands. Tolhuisweg 24a, 9475 PG, Midlaren, The Netherlands. Tel: 31-6-3629-0124. \\ E-mail: w.m.geerts@nhl.nl
}

Received: August 23, 2017

Accepted: September 30, 2017

Online Published: December 22, 2017

doi:10.5539/ies.v11n1p64

URL: https://doi.org/10.5539/ies.v11n1p64

\begin{abstract}
Video footage is frequently used at teacher education. According to Sherin and Dyer (2017), this is often done in a way that contradicts recent studies. According to them, video is suitable for observing and interpreting interactions in the classroom. This contributes to their situated knowledge, which allows expert teachers to act intuitively, immediately and effectively. Situated knowledge is used to give form (design patterns) and direction (educational purposes) to a teacher's actions. Design patterns consist of solutions for recurring problems. In the current research, we investigated whether a course in classroom management either with or without video cases contributes more to the development of situated knowledge, design patterns and educational purposes. The preand posttest are based on a written advice, given out by 41 students of the Dutch hbo-teacher training with an average age of 22, to the main character of a video case, in addition to an interview and observation report. The results indicate that the use of video cases does not lead to an increase in the number of educational purposes. There is an increase, however, in the design pattern 'classroom management'. By internalizing this design pattern, the divide between theory, practical experiences and the identity of the teacher is bridged. Although the classroom management theme dominated the video case and course, the results indicate that a targeted use of video cases in teacher education is effective in promoting the development of situated knowledge.
\end{abstract}

Keywords: loop learning, pre-service teacher, reflection, situated knowledge, teacher training, video case

\section{Introduction}

\subsection{The Expert Teacher}

Training better teachers is a necessary end, as teachers are the key factor in facilitating the learning process of their pupils. Better trained teachers can potentially become experienced teachers, or experts. Experts know instinctively how to act in the dynamic environment that is their daily workplace. Being effective in the classroom has to do with both the contents of the course the teacher is teaching, as well as managing the classroom. The current research focuses on the latter: general teaching skills, and not on didactical knowledge in the form of Pedagogical Content Knowledge (PCK) (Shulman, 1987; Geveke, 2016).

When managing a class, an expert teacher can recognize meaningful patterns in practice and knows how to react to them (Boshuizen, 2009; Lesgold, Greeno, Glaser, Pellegrino, \& Chase, 1988). Meaningful patterns are regularities in workplace situations as they develop. By identifying them, experts get clues as to their best course of action, because they get an insight in the underlying principles and the deeper meaning of situations. Although experts thus know how to react effectively to their surroundings, this does not mean they explicitly form strategies before they act. Their actions are intuitive, but well substantiated and of expert nature. Further, their actions are tied to the professional situation that presents itself and are formed by the expert's perception of that situation: their actions are domain specific (Sheridan \& Reingold, 2011). But what does this mean? It is important to note that this domain specific knowledge is situated.

\subsection{Situated Knowledge}

Situated knowledge is defined as knowledge that arises from, and is connected to, the interactions between his material body and the physical environment the action takes place in. The situated aspect of this knowledge 
becomes apparent from the fact that it is triggered by this situation, contains all relevant aspects of that situation (holistic) (Putnam \& Borko, 1999), applies only to that specific situation (Geerts, Van der Werff, Hummel, Steenbeek, \& Van Geert, 2015) and grows with every interaction in that situation (Kim, 2011). The connection between situated knowledge and the context means that its elements are inextricably connected to the situations, interactions and activities in which they occurred, and are therefore of an embedded nature (Brown, Collins, \& Duguid, 1989). Every new experience with that situation, interaction or activity adds something to the situated knowledge. For example, when teaching a high school class, a teacher might use a certain strategy to contain a disruption. As he is doing this, he relies on his situated knowledge. Relevant information about the situation is stored, irrelevant information is discarded. Because of this selection process, experienced teachers have access to an increasing amount of situated knowledge, which allows them to act effectively in such situations (Haider \& Frensch, 1996; van Meeuwen et al., 2014).

It should be emphasized that not only experience with a situation, but also the perception of that situation and the way it is mentally projected, affect the way the teacher is effective (Wolff, van den Bogert, Jarodzka, \& Boshuizen, 2015). A novice teacher will only see superficial elements in his classroom, but the expert teacher will have noticed crucial details. His experience allows him to see specific things to base his actions on in that situation. He uses this skill to focus on the most important aspects of the educational situation at hand. This way, by using his situated knowledge, his mental representation of it will be more accurate (Carter \& Doyle, 1987; Borg, 2015). Transfer of this knowledge is difficult, as the expert's knowledge is implicit and embedded in the social context of the classroom. Transfer can only occur when the knowledge is joined with the situation it is embedded in. This process requires effort, reflection and coordination (Lam, 1997; Mor \& Havery Warburton, 2014).

\subsubsection{Classroom Management}

Being effective in the classroom not only follows from mastering the contents of the course, but also for a large part from the associated skill of classroom management. Both are conditional for establishing a rich learning environment in which pupils can perform optimally. Classroom management is defined by Brophy $(2006 ; 1988)$ as "actions undertaken to create and maintain an environment to successfully give instructions in: setting up rules and procedures, arranging the physical space, holding the pupils' attention and managing activities (2006, p. 17)". To successfully carry out these actions, the teacher needs to recognize the relevant signals and events in the classroom. Because any classroom has a wide variety of signals and events, recognizing them is a complex cognitive process (Berliner, 2001; Copeland et al., 1994; Van Es \& Sherin, 2002).

The embedded situated knowledge provides the experience necessary to know where to focus the attention and which pieces of information are relevant. Two aspects of their actions are particularly important here: alertness to identify an event and the ability to choose the right action in the form of productive interactions. How both aspects are used by the teacher determines how he can create a learning environment effectively.

\subsubsection{Alertness as an Example of an Educational Purpose}

Alertness is the teacher's ability to be constantly aware of what is going on in the classroom (Kounin, 1970, Christofferson \& Sullivan, 2015). Not only the way this is perceived, also the way these perceptions are interpreted, how signals are received and how problems are anticipated is part of alertness. A teacher bases his decisions regarding the actions he will take to protect and improve the productive climate in the classroom on his alertness. This alertness applies also to any situation that is familiar to the teacher. The relevant aspects of such a situation are closely tied in with this situation, and so it follows that the teacher's alertness is a consequence of his situated knowledge.

Copeland and D'Emidio-Caston (1998) call any choice for an action in a specific situation an educational purpose. Educational purposes are the constantly changing process goals which a teacher determines for himself and allow him to direct the lesson in a way he decides is best. They are based on the principles the teacher acquires during his training (Copeland \& D'Emidio-Caston, 1998). A principle is an underlying conviction that determines the constantly changing process goals. For classroom management the teacher realizes, for example, that he must be alert to be able to take corrective action, is responsible for a lesson's momentum, and has to be in charge to successfully manage the group. It is important to note that an educational purpose is not a lesson goal or objective, but a process goal a teacher sets for himself while performing the lesson.

Educational purposes determine what a teacher pays attention to and where his alertness is focused. Specific educational purposes arise depending on the underlying principles a teacher carries, his ideas on what makes a good lesson, his previous experiences with teaching situations and the connections with the theory that he establishes. Such educational purposes are situated and they develop as situated and embedded knowledge. This 
means that once acquired, educational purposes are used intuitively, are implicit and linked to a particular context. It also means that an experienced teacher has already, intuitively, carried out his actions before he can make his reasoning behind it explicit. Both the experienced teacher as the one in training can, however, be made aware of their educational purposes by asking him about it, which allows him to translate this broad, theoretical concept into less abstract terms. Specifically, this can be done with the educational purpose operationalization developed by Copeland and D'Emidio-Caston (1998), which asks eight questions about: purpose statements, practical generalizations, guiding principles, theory links, action links, justified changes, positive evaluative statements, and negative value judgements.

\section{3 'Dealing with Disorder': An Example of a Design Pattern}

A teacher's ability to be alert to his surroundings only becomes productive once his reactions are alert as well. And his reactions, together with the interactions that are based on it, become productive only once they are combined with the goal the teacher intended. The teacher uses his educational purposes to determine which actions can contribute to achieving the goal. In case a teacher sets 'teaching a lesson that flows smoothly' as a process goal, this goal decides which actions he will then take. Having the actions correspond to the process goal does not mean these interactions will be effective. The extent to which a teacher can employ such interactions productively and efficiently depends on his previously acquired situated knowledge.

Alexander calls a series of efficient interactions that are used as a solution to a recurring problem a design pattern (Alexander et al., 1977). Such a solution consists of a structure of heuristics (global procedures) (Goodyear et al., 2004). Because a teacher acts practically and intuitively, he applies such a design pattern more or less automatically. For example, an experienced teacher focuses his attention to the proceedings in the classroom that surround the pupils' learning process. He might, for example, look at classroom management issues from different perspectives, keep an eye on continuity and act before they can become an issue (Wolff, Jarodzka, van den Bogert, \& Boshuizen, 2016). This means that design patterns are not internally represented potential actions that are free of context, but instead, instances of situated knowledge.

To explicate design patterns further, we will now give an example that concentrates on dealing with disorder. The context, in this case, is a group of pupils that keeps disturbing the teacher's instruction, even when they have been given a warning. The group is part of a class of first year secondary school students, and the lesson is taught on a late Friday afternoon. The design pattern 'dealing with disorder' is used to put an end to repeated chitchatting or disturbances of the productive climate. One way of doing this is by making the instruction more exciting. An experienced teacher will apply this automatically, but a teacher in training has yet to learn this. While doing so, he is assisted by making a written preparation of the instruction, or by practicing with the execution of the lesson. In conclusion, one of the elements of the design pattern 'dealing with disorder' can be used: communication, momentum, being alert, multi-tasking, signaling to pay attention, pupil-responsibility and conflict management (Geerts \& Van Kralingen, 2016).

\subsubsection{Pattern Language}

Another characteristic of design patterns is that they exist in groups, which form pattern languages, with a general purpose. A pattern language is a cluster of design patterns, used for a specific domain (Powell, Millwood \& Tindal, 2008). In case of the above example, when a teacher engages the disorderly class by using a more exciting instruction, the teacher not only uses the design pattern 'dealing with disorder', but also the design pattern 'instruction'. The design pattern 'dealing with disorder', is tied in with the overarching pattern language 'teaching', which in turn consists of subordinate design patterns like 'pedagogical action', 'dealing with personal characteristics', 'reflecting', 'giving instructions' and 'guiding the learning process'.

Developing a pattern language is, just like other forms of situated knowledge, a long-term process. For the teacher, the process of acquiring a pattern language is iterative (Rusman et al., 2009). It starts with an analysis of the current situation, individualistically figuring out a solution to the problem and then evaluating its results. The result of this cycle forms the input and starting point for the next cycle. Increasingly better solutions are reached by repeating this process, because for each domain multiple design pattern based solutions are possible (Kolfschoten, Lukosch, Verbraeck, Valentin, \& de Vreede, 2010). The teacher judges his actions in the situation by determining to what extent they have contributed to reaching the desired goal. In this way, the teacher gradually accumulates increasingly refined design patterns, which form the basis of a pattern language. And in this process, his expertise grows.

\subsubsection{Design Patterns at the Teacher Training}

The teacher education's task is to support teachers in acquiring the situated knowledge they need to function 
effectively in the complex environment that is the classroom (Carter \& Doyle, 1987; Borg, 2015). A teacher in training can be viewed as a novice who has a long way to go before he reaches the level of a starting expert. After his initial education, he can grow to become an experienced teacher by gaining an increasingly rich aggregation of educational purposes and design patterns, coordinated in pattern languages.

Recent studies of competence acquisition increasingly focus on the contrast between the way expert and novice teachers experience events in the classroom (van den Bogert, van Bruggen, Kostons, \& Jochems, 2014). This includes all aspects of situated knowledge in an experienced teacher, including the difference between the ways in which both are alert to classroom management issues. Echoes of this research at the teacher education lead to an increased attention to possible ways of transferring the necessary knowledge and heuristics (HBO-council, 2011). Heuristics deal mainly with the way interactions can occur in the classroom. The report by the HBO-council defines heuristics as context-specific rules of thumb to deal with a specific kind of problem. In addition, the fact that heuristics are, in fact, good examples of situated knowledge, means that acquiring them is a long-term iterative process, for which the context is a crucial element. And because the practical experience of individual teachers in training is limited, it is no surprise that acquiring design patterns, in the form of situated knowledge, is a challenging task for them. Acquiring design patterns in the form of declarative knowledge is relatively simple, but of little use for improving concrete actions.

\subsubsection{The Use of Written Design Patterns}

There is a disparity between the way an experienced teacher acts effectively by intuition, and the relative inability of novice teachers to be effective in the dynamic classroom that is their daily environment. As he is starting out, the novice teacher can only employ his explicit and self-moderated knowledge, which becomes increasingly automated and internalized, and in this way, situated knowledge. This acquisition model corresponds to several other theories on knowledge becoming internalized, in particular Vygotsky's concept of the zone of proximal development and Gal'perin's theory on the internalization of knowledge (Derry, 2013). Gal'perin posits that the process of internalizing knowledge starts out with explicit knowledge that is used with the support of a competent partner, for example the teacher trainer who supports the novice in his learning. To support this internalization process, the educational publications that are used at the teacher education schools often contain written solutions to problems (Geerts \& Van Kralingen, 2016). These are educational situations that have been written down in full and contain the following elements:

- an example that is characteristic of the design pattern;

- $\quad$ an introductory description of the context and its place within a pattern language;

- examples of solutions, described in practical steps;

- a conclusion, including a description of other design patterns and how they relate to other design patterns (Borchers, 2008; Kolfschoten, Lukosch, Verbraeck, Valentin, \& de Vreede, 2010; Powell, Millwood, \& Tindal, 2008).

However, such a theoretical description can only become part of a teacher in trainings situated knowledge once he links it to his real-world experiences. Without this link, all he has is a memorized, strongly simplified and formalized version of reality, which cannot be implicitly and instinctively used. The theoretical description can serve as a starting point for an improved way of training teachers: one that focuses on internalizing design patterns. Sherin \& Dyer's idea is that "if teachers "see" theory in practice, they will more easily be able to understand and adopt similar approaches" $(2017$, p. 50). They go on to say that research has shown that "without a deep understanding of the practices they observe, teachers may not be able to implement a new pedagogical strategy as it was intended (Blomberg et al., 2014)". The first step towards linking theoretical descriptions to practical experiences is identifying design patterns. This is in accordance with other current findings that indicate that guided inquiry learning is effective. This type of learning assumes an active teacher role (van Vondel, Steenbeek, van Dijk, \& van Geert, 2017).

\subsubsection{Higher Learning Objectives}

Before design patterns can be developed, the teacher in training must have educational purposes. These are not learned from a book, and acquiring them requires a processing that is more thorough than merely remembering. For instance, the situation needs to be analyzed, or the teacher's actions evaluated. In this, he can be supported, and support can come from a more competent other, like a teacher trainer or supervisor. In this situation, there is explicitly formulated knowledge that is supported by the social environment. The necessity to analyze a situation means that when training new teachers, the educational facility needs to work with higher learning objectives.

Higher order learning objectives are learning objectives that require higher order thinking skills, such as 
analyzing, evaluating or creating study materials. These skills require more cognitive skills that lower order objectives like remembering, understanding and applying (Jensen, MacDaniel, Woodard, \& Kummer, 2014; Bloom, 1984). This proposed way of teaching design patters means that, even before a teacher can act in an educational setting, he must be able to understand or give meaning to what is going on in that setting (Blanton, Blanton \& Cross, 1994). Written design patterns can serve, as they contain a conceptual framework to describe the situation. To indeed understand the situation, however, he should be challenged to reflect on his practical experiences, including his educational purposes and evaluating the results of his new design patterns. This evaluation requires higher cognitive functions, so this way of learning ranks higher in the taxonomy of learning objectives. A teacher in training must be able to distinguish important aspects of the situation he is presented with (Masats \& Dooly, 2011).

\subsubsection{Videocases}

A teacher trainer that employs higher order learning objectives to impart design patterns and pattern language as situated knowledge in his students, can make use of video cases in achieving those objectives (Geerts, Van der Werff, Hummel, Steenbeek, \& Van Geert, 2015).

Using video cases comes with several advantages compared to cases on paper, besides the latter being colored by the author's vision (Blijleven, 2005). First, video cases contain a great deal of explicit details of the recorded situation, which are presented contextually and holistically. Information and scenarios are shown in a way that corresponds to the way real teachers encounter didactical and pedagogical problems (Blijleven, 2005; Geerts, Van der Werff, Hummel, \& Van Geert, 2015). Second, video cases allow teachers in training to apply their theoretical knowledge by analyzing a specific, authentic educational situation. By examining the actual behavior of a teacher handling a certain situation on video, they can explore how he deals with that situation (Blijleven, 2005; Kurz, Llama, \& Savenye, 2004). Compared to a written case study, a video recording does not contain a textual interpretation that steers the reader. Instead, it allows that viewer to consider the educational situation objectively without being colored by the interpretation of whoever is presenting the case (Rosaen, Lundeberg, Cooper, Fritzen, \& Terpstra, 2008; Van Es \& Sherin, 2002).

Of course, a video is also recorded from a distinct visual perspective. But in the production process, the producers might choose to record using several visual perspectives, as was the case with Didiclass ${ }^{1}$, whose video database is used in the current research. The Didiclass team explicitly stated their intention to produce realistic videos that capture a multilayered reality, while keeping the corresponding pluri-interpretability intact. By taking multiple perspectives, for example both the students and teachers perspective, the viewer can form a fuller picture of the real world educational situation. Third, authentic videos have both the situated and embedded aspects of the recorded situation captured by the camera. Fourth, teachers in training, by analyzing educational videos, can become convinced that they will be able to obtain the skills, knowledge and attitudes that are necessary to function effectively as a teacher (Shulman, 1992). Fifth, these video-cases can be looked at in the relative peace of the training institutes environment. Because the viewer has time to react, he is challenged to put into words his own ideas, feelings and interpretations. These advantages make that authentic video cases are particularly well-suited to have a teacher in training: analyze the scene presented in the video, make the educational purposes their own and come up with solutions to reach the process goals he set by applying a design pattern, in the form of situated knowledge. As it turns out, when using video cases, teacher trainers focus insufficiently on higher learning objectives, which could support the development of situated knowledge. This poses the question whether teacher trainers are fully taking advantage of the benefits of authentic video cases.

\subsection{Aims of This Research}

The current research aims to study whether the proposed use of video cases based on optimized authenticity can indeed contribute to the acquisition of situated knowledge in the form of design patterns and educational purposes by teachers in training. Specifically, this study will look at the use of video cases in a classroom management course during the $2^{\text {nd }}$ year of the teacher education, and what it can contribute to the acquisition of higher learning objectives, in the form of reflecting on design patterns and educational purposes. Due to the curriculum and the timing of the internships, this course is only taught in year two.

The main research question is: to what extent does the use of video cases in a classroom management course contribute to the development of 1. situated knowledge in the form of educational purposes, specifically 2. the design pattern 'dealing with disorder' and 3. the overarching pattern language 'teaching'. These corresponding predictions have been formulated:

Hypothesis 1: Teachers in training who are taking a course that uses video cases can connect more educational purposes to the real-world situation presented in the video compared to teachers in training who are taking the 
course but without video cases.

Hypothesis 2: Teachers in training who are taking a course that uses video cases can connect more components of the pattern language 'teaching' to the real-world situation presented in the video than teachers in training who are taking the course without video cases.

Hypothesis 3: Teachers in training who are taking a course that uses video cases show more development of the design pattern 'dealing with disorder', compared to teachers in training who are taking the same course without video cases.

\section{Method}

\subsection{Participants}

In this research, 41 teachers in training from two parallel groups of second year English teachers in training (full-time) at the NHL University of Applied Sciences have been examined. The participants were randomly divided into either the control group or the experimental group. The control group attended the regular course with written or verbalised cases, as it had been taught at the school before. The experimental group attended the experimental version of the course which included lessons with video cases. The duration of the course was two months and a measurement was done at the beginning as well as the end of the course. At the start of the course the experimental group consisted of 21 teachers in training. However, seven of them had quit immediately after the beginning of the course and five students left the course at a later point. For that reason, the experimental group eventually consisted of 3 males and 6 females $(\mathrm{N}=9)$ with an average age of $21.78(\mathrm{SD}=1.20)$. Initially, there were 20 teachers in training in the control group, of whom six quit immediately after the start of the course. Six others dropped out as the course progressed. Consequently, one male and seven females were in the control group with an average age of $22.25(\mathrm{SD}=2.38)$. The drop-out rate, as well as composition of the groups reflects the nature of the student body at the English teacher education. Most of the teachers in training who dropped out have left the educational program. The high rate of drop-out is in line with nation-wide data of second degree teacher educational programs (Inspectie van het Onderwijs, 2014). Therefore, the remaining groups correspond in terms of age, pre-education, number of obtained credits, underlying motivation for the profession and largely regarding gender distribution.

\subsection{Materials}

For the pre- and post-test, a measuring instrument has been developed, which measures the educational purposes, the pattern language 'Teaching' and the design pattern 'Dealing with disorder', with which hypothesis 1, 2, and 3 can be answered. The instrument consists of three assignments: creating a written advice for the main character 'Olga' in the viewed video case, writing an oral observation report using the participants' educational purposes and a structured interview about the design pattern 'Dealing with disorder'. Both the observation report and the interview were recorded with a video recorder and then a transcription was made from the recording. All the components of the measuring instrument were completed by the participants in above stated identical order.

It was decided to rely on the measuring instrument Observation Report to explore which educational purposes are present (hypothesis 1). Eight cards were used to operationalize educational purposes and challenge the respondents to connect educational purposes to the viewed video case. The Observation Report is thus aimed at hypothesis 1: educational purposes.

By using the measuring instrument 'written advice', the advice the respondent would give in the situation portrayed in the video through a number of questions was recorded. From the answers, it can be inferred how many components of the pattern language "Teaching" are used in the advice. Following the professional requirements used in The Netherlands (Ministerie van Onderwijs, Cultuur en Wetenschap, 2017), the pattern language "Teaching" had for this research initially been defined as pedagogical action, dealing with human characteristics, reflection, providing instruction, guiding the learning processes, and dealing with disorder. This classification has been secondarily validated by several experienced teacher trainers. This validation took place in 2012, at the annual congress for the occupational group of teacher trainers from The Netherlands and Belgium that took place in Antwerp (Velon, 2012). At the congress, during a workshop the entire survey was done by thirty teacher trainers, highly experienced in teaching secondary education classes. From the answers of these experienced teacher trainers, high conformity was apparent regarding the mentioned components of the pattern language 'Teaching'.

To obtain a better insight into the given answers, it was decided to examine which components of the pattern language 'Teaching' were used the most in the Observation Report. The measuring instruments 'written advice' and Observation Report are thus both aimed at hypothesis 2: pattern language 'Teaching'. 
Using the answers to the questions from measuring instrument Interview, it was determined to what extent the design pattern 'Dealing with disorder' has been mastered. The questions in the interview are based on ideas on dealing with disorder from the Handbook for Teachers (Geerts \& Van Kralingen, 2016). In summary, the following components of the design pattern 'Dealing with disorder' are considered: communication, fluent lesson progression, reacting alertly, multi-tasking, 'pay attention' signals, student responsibility and conflict handling. The Interview is thus aimed at hypothesis 3: design pattern 'Dealing with disorder'.

The first instrument that was used, the Written Advice, is aimed at the overall picture that the respondent has of the situation. Only with the second instrument the respondent was invited to connect situated knowledge to the situation at a more detailed level. This sequence of conducting the measuring instrument was used to prevent the respondents from falling back on theoretical knowledge from a course book, which is not connected to the situation. Finally, because of the importance of a uniform way of conducting, the choice had been made to have all instruments conducted by a student-assistant.

The video case that was used (casus 'Olga') is part of Didiclass (Geerts, Van Laeken, \& Mitzschke, 2007), which comprises a series of cases widely used in the Dutch teacher education programmes. The subjects of the cases are engaging for teachers in training as they offer real-world situations, and feature a wide variety of central figures teaching (male, female, young and old). The case Olga has been chosen because the contents of the case are in line with the subject of the course, classroom management, and keeping order. The case illustrates all components of the design pattern 'Dealing with disorder' and consists of three short videotaped clips. In the first clip Olga is shown as she tells something about her functioning. In the second, four-minute clip, parts of her lesson are shown in chronological order: Olga teaches German in a second year VMBO-T-class. At the beginning of the lesson she teaches, she loses the flow in the way the lesson progresses (momentum), which results in the lesson getting a rough start. Only halfway through the lesson she is finally able to begin the lesson she prepared. The third clip lasts almost three minutes and is a report by two students who have been removed from the lesson by Olga. The students' reflections in the clip are supported by lesson fragments.

\subsection{Procedure}

The candidates all attended a classroom management course, consisting of eight weekly meetings of one and a half hours. The control group attended the regular course with written or oral cases; the experimental group attended an experimental version of this course, designed by using various other video cases from the case database Didiclass (Ruud de Moor Centrum, 2007). In this experimental group, the emphasis of the course was therefore on the situated nature of acquiring educational purposes and design patterns. At the beginning and end of the course, a pre- and post-test were conducted by employing the measuring instruments mentioned above. The respondents were obligated to take part in these. The Olga case outlined is used in both the pre- and the post-test, but not during the course. Since the pre-test was conducted with both the experimental and the control group, and feedback was not provided, it is expected that a possible learning effect for the experimental group is equivalent to that of the control group.

\subsection{Analysis of the Variables}

\subsubsection{Educational Purposes}

The oral observation report that was made after the participants watched the video case 'Olga' was used to map out the development of their educational purposes. An example is: 'I can see that you give out warnings, but that you don't follow up these warning with consequences. After a second warning you should act, otherwise students become aware that all you do is threaten'.

In terms of educational purposes, this quote is ranked as 'justified change', because a motivation is given for the advice. This motivation is linked to what the teacher in training has seen in de video.

\subsubsection{Pattern Language}

To determine the size of the pattern language the number of the design patterns present were measured: pedagogical action, dealing with human characteristics, reflecting, performing instructions, guiding the learning process, and dealing with disorder. Whenever a given answer could be attributed to two different design patterns, the context of the complete answer to the question was judged to determine what the correct coding should be. The coding instructions were adjusted accordingly. By changing the instructions and not re-structuring the instrument itself, an accurate comparison between the groups of respondents was possible, while the respondents did have the ability to, in their own words and without much guidance, answer the questions (Gibb, 2008). 


\subsubsection{Design Pattern 'Dealing with Disorder'}

In the interview, the quality of the design pattern 'dealing with disorder' is determined by questioning the teacher in training about different applicable steps that are part of this design pattern, that is: communicating effectively, handling conflict, continuous signal, alertness, overlapping, the ability to keep students paying attention, student responsibility (Geerts \& Van Kralingen, 2016).

Every applicable step has been questioned separately. For each correct part of the answer the teacher in training could receive a point. He could be awarded a point for expressing each of the following elements: a) a good observation of the viewed video case, b) a connection between theory and daily practice, c) a personal practical experience, d) an applicable suggestion for improvement of the appropriate action. So, a total of four points can be scored. Provided that a teacher in training has scored three points or higher, there is a reasonable suggestion that he has the situated knowledge to exercise the design patterns in a practical situation. The following quantitative evaluation has been used: Insufficient for zero points, weak for one point, beginner for two points, and applicable for three or more points.

Because of the small sample size, a Monte Carlo Simulation (Todman \& Dugard, 2001) was subsequently performed on both the results of the control and the experimental group. This was done to be able to, based on these simulations, make assumptions with regards to the probability distribution. Using this technique, the observed findings have been simulated many times based on a zero-hypothesis model, to be able to say something about the probability that the scores taken at several measuring moments have been based on coincidence. These simulations consist of random permutations of the observed outcomes. By randomly shuffling the observations 10.000 times, randomly shuffled sets are formed, each of which is an operationalisation of the possible outcome under the zero hypothesis. Whether the empirically detected variances, for example those between the experimental and control condition, under the zero hypothesis, can be expected on the bases of coincidence, can be determined in this way. The result of this collection of simulations is a distribution function that shows the total range of possible outcomes (Landau \& Binder, 2015). During the analysis, it was determined whether there are any statistical significant differences, both in terms of the pre-and post-test and the control and experimental group.

To gain a better understanding of the effect size between the groups, Cohen's $d$ has been calculated where possible. The effect size can be expressed in both a positive and a negative value. In this case, a positive effect size value indicates that learning had occurred, whereas a negative value indicates a learning loss. Following the guidelines set by Cohen (1977), a Cohen's d value between 0.0 and (-) 0.2 cannot be called an effect. A value between (-)0.2 and (-) 0.5 means a small effect occurred and there is a moderate effect when the value is between $(-) 0.5$ and (-)0.7. A value over (-)0.7 indicates a consequential or large effect.

The results are reported using a combination of Cohen's $d$ for effect size and an exact p-value. The p-value is reported to indicate the probability of the result that was observed. A p-value smaller than 0.1 but over 0.05 , for instance, indicates that it is probable that the observed values are not the product of random chance (Cumming, 2014; Kline, 2013; Lambkin, 2012). A p-value smaller than 0.05 indicates that it is very unlikely the product of random chance, and a p-value smaller than 0.001 means it is extremely unlikely. The p-value is combined with Cohen's D to make statements about the difference between both groups in the experiment. A meaningful difference is established with a $p<0.05$, combined with a $d>0.7$. If the $d$ 's value, however, for the same p-value falls between 0.5 and 0.7 , there is a moderately meaningful difference. Finally, a $d$-value below 0.5 , for the same $p$-value, indicates a difference of limited meaning. As the $p$-value increases and the effect size becomes smaller, the results become progressively less meaningful.

\section{Results}

\subsection{Hypothesis 1: Number of Educational Purposes}

During the pre- and post-test, the participants used cards to link educational purposes to the video case they watched. Table 1 shows the number of educational purposes, out of a maximum of 8 , that were linked by the participants. It shows that the experimental group scores lower both on the pre-test $(M=6.4, S D=1.33)$ and the post-test $(M=6.4, S D=1.33)$, than the control group on the pre-test $(M=7.75, S D=0.7)$ and the post-test $(M=$ $7.25, S D=0.89$ ). The effect size stated as a difference between the pre-test and the post-test is $d=-0.67$, $p<0.001$ for the control group, a moderately meaningful difference. In the experimental group, there is no difference between the pre- and post-test, and consequentially there is no effect at all in this group. For the control group, there even appears to be a moderately sized learning loss. A moderately meaningful difference was observed between the experimental group and the control group $(d=0.537, p=0.038)$. This is contrary to our expectation that the experimental group is able to list more educational purposes. The observed learning loss 
is more pronounced in the control group compared to the experimental, however.

Table 1. Number of educational purposes linked to the video case for each participant

\begin{tabular}{ccccccccccccc}
\hline Ptc. & \multicolumn{1}{c}{ Experimental group } & \multicolumn{1}{c}{ Control group } \\
\hline & Pre & M & SD & Post & M & SD & Pre & M & SD & Post & M & SD \\
\hline 1 & 8 & 6.4 & 1.33 & 8 & 6.4 & 1.33 & 8 & 7.75 & 0.70 & 8 & 7.25 & 0.89 \\
2 & 8 & & & 7 & & & 8 & & & 6 & & \\
3 & 8 & & & 7 & & & 8 & & & 8 & & \\
4 & 5 & & & 7 & & & 8 & & & 8 & & \\
5 & 6 & & & 6 & & & 8 & & & 7 & & \\
6 & 5 & & & 6 & & & 8 & & & 8 & & \\
7 & 7 & & & 7 & & & 8 & & & 7 & & \\
8 & 6 & & & 6 & & & 6 & & & 6 & & \\
9 & 5 & & & 4 & & & & & & & & \\
\hline
\end{tabular}

\subsection{Hypothesis 2: Elements of Pattern Language 'Teaching'}

\subsubsection{Pattern Language 'Teaching' in Written Advice}

To compare pattern languages, the clusters of design patterns they consist of were examined. It was decided to compare the quantities of the design patterns that were mentioned by the participants in both the experimental and the control group during the pre- and post-test. The results are presented in table 2 (experimental group) and 3 (control group).

Table 2. Number of design patterns mentioned in the written advice - Experimental group

\begin{tabular}{lcccccccccccccc}
\hline Participant & \multicolumn{1}{c}{ Pre-test } \\
\hline Question & 1 & 2 & 3 & $\mathrm{a}$ & $\mathrm{b}$ & $\mathrm{M}$ & $\mathrm{SD}$ & 1 & 2 & 3 & $\mathrm{a}$ & $\mathrm{b}$ & $\mathrm{M}$ & $\mathrm{SD}$ \\
\hline 1 & 1 & 2 & 2 & 2 & 3 & 2 & 0.71 & 2 & 2 & 1 & 2 & 2 & 1.8 & 0.45 \\
2 & 2 & 3 & 2 & 2 & 0 & 1.8 & 1.10 & 1 & 2 & 2 & 1 & 1 & 1.4 & 0.55 \\
3 & 1 & 2 & 2 & 2 & 0 & 1.4 & 0.89 & 1 & 2 & 1 & 1 & 1 & 1.2 & 0.45 \\
4 & 1 & 2 & 2 & 2 & 0 & 1.4 & 0.89 & 1 & 3 & 3 & 3 & 1 & 2.2 & 1.10 \\
5 & 1 & 1 & 2 & 1 & 1 & 1.2 & 0.45 & 3 & 3 & 3 & 2 & 2 & 2.6 & 0.55 \\
6 & 2 & 2 & 1 & 4 & 1 & 2 & 1.22 & 1 & 2 & 1 & 1 & 1 & 1.2 & 0.45 \\
7 & 1 & 2 & 1 & 1 & 1 & 1.2 & 0.45 & 2 & 2 & 1 & 2 & 1 & 1.6 & 0.55 \\
8 & 1 & 2 & 1 & 1 & 1 & 1.2 & 0.45 & 3 & 3 & 2 & 2 & 2 & 2.4 & 0.55 \\
9 & 2 & 2 & 1 & 1 & 0 & 1.2 & 0.83 & 2 & 2 & 2 & 2 & 0 & 1.6 & 0.89 \\
\hline
\end{tabular}

Table 3. Number of design patterns per question mentioned in the written advice - Control group

\begin{tabular}{lcccccccccccccc}
\hline Participant & \multicolumn{1}{c}{ Pre-test } \\
\hline Question & 1 & 2 & 3 & $\mathrm{a}$ & $\mathrm{b}$ & $\mathrm{M}$ & $\mathrm{SD}$ & 1 & 2 & 3 & $\mathrm{a}$ & $\mathrm{b}$ & $\mathrm{M}$ & $\mathrm{SD}$ \\
\hline 1 & 3 & 3 & 3 & 2 & 0 & 22 & 1.30 & 3 & 4 & 3 & 3 & 1 & 2.8 & 1.10 \\
2 & 2 & 1 & 1 & 1 & 1 & 1.2 & 0.45 & 1 & 2 & 2 & 2 & 1 & 1.6 & 0.55 \\
3 & 2 & 2 & 3 & 2 & 2 & 2.2 & 0.45 & 2 & 2 & 3 & 2 & 2 & 2.2 & 0.45 \\
4 & 1 & 3 & 3 & 3 & 2 & 2.4 & 0.89 & 1 & 2 & 1 & 1 & 1 & 1.2 & 0.45 \\
5 & 2 & 3 & 2 & 2 & 2 & 2.2 & 0.45 & 1 & 3 & 2 & 2 & 2 & 2 & 0.71 \\
6 & 2 & 2 & 3 & 2 & 2 & 2.2 & 0.45 & 1 & 4 & 3 & 3 & 2 & 2.6 & 1.14 \\
7 & 2 & 3 & 2 & 2 & 2 & 2.2 & 0.45 & 1 & 2 & 1 & 1 & 1 & 1.2 & 0.45 \\
8 & 3 & 2 & 2 & 2 & 2 & 2.2 & 0.45 & 3 & 4 & 3 & 3 & 3 & 3.2 & 0.45 \\
\hline
\end{tabular}

The values of the experimental group indicate progress between the pre- $(M=1.49, S D=0.39)$ and post-test $(M$ $=1.78, S D=0.51)$. The control group shows no such progress between the pre- $(M=2.1, S D=0.37)$ and post-test $(M=2.1, S D=0.74)$. This suggests that the experimental group has made more progress than the control group. The observed difference between the pre- and post-test is significant for the experimental group $(d$ $=0.698, p<.001$ ), which is interpreted as a moderately meaningful difference.

Next, the design patterns that were mentioned for each question in the written advice were listed. The results of 
the pre-test illustrate the distribution of the responses (see Figure 1). This distribution was not tested: as the second hypothesis is used to investigate the number of design patterns, just the total number of design patterns mentioned is relevant for the intervention. Specifically which design patterns have been named is, in the context of the current inquiry less important.

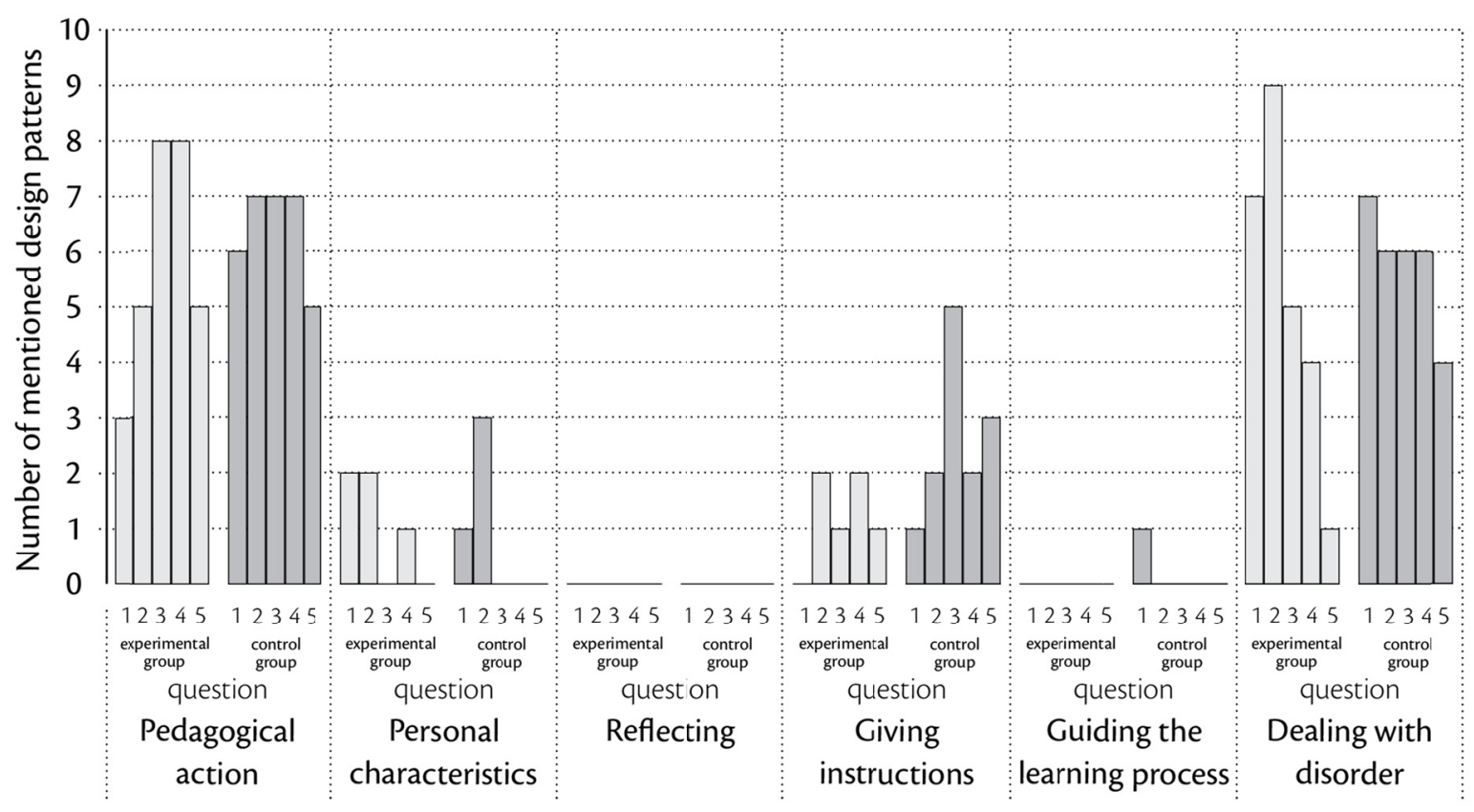

Figure 1. Design patterns mentioned per questions (pre-test)

The most frequently mentioned design patterns were 'pedagogic action' and 'dealing with disorder'. They were mentioned at each question, but mainly when sharing the advice and when composing concrete, applicable advice. During the pre-test, participants in the control group more often mention the design pattern 'instruction', compared to the experimental group. Figure 2 shows how, during the post-test, there was more proportionality in the frequencies of design pattern mentions, but also how pedagogic action, instruction and dealing with disorder still come up most frequently. Here, instruction is mentioned more often by the experimental group than the control group.

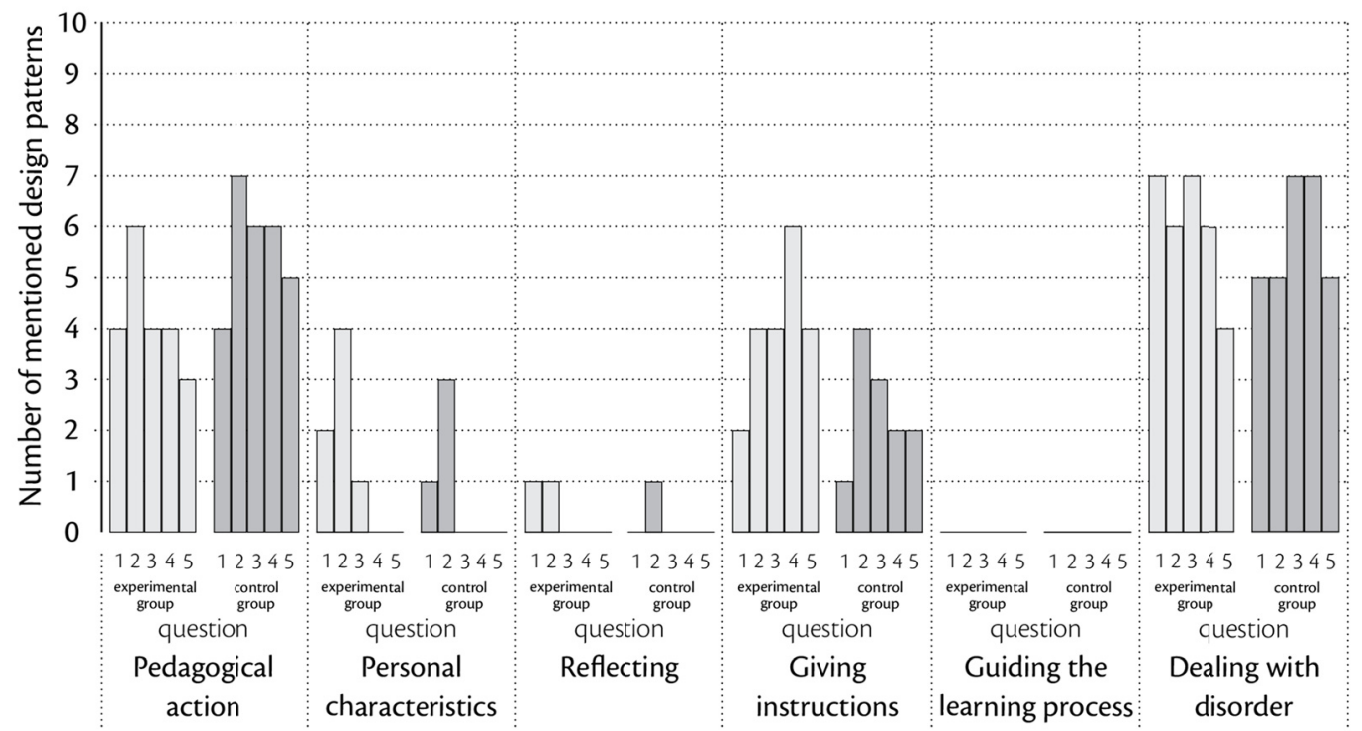

Figure 2. Design patterns mentioned per questions (post-test) 


\subsubsection{Pattern Language 'Teaching' in the Oral Observation Report}

As a result the participants were able to link most of the educational purposes to the video case. To get a better understanding of these answers, it was decided to investigate the number of design patterns of the pattern language 'teaching', per respondent, that occurred in the answers (Table 4).

Table 4. Number of design patterns - oral observation report

\begin{tabular}{ccccccccccccc}
\hline Ptc. & \multicolumn{3}{c}{ Experimental group } & \multicolumn{1}{c}{ Control group } \\
\hline & Pre & M & SD & Post & M & SD & Pre & M & SD & Post & M & SD \\
\hline 1 & 13 & 10.44 & 3.0 & 11 & 11.33 & 2.65 & 22 & 13.13 & 4.45 & 16 & 11.38 & 3.34 \\
2 & 15 & & & 15 & & & 16 & & & 9 & & \\
3 & 14 & & & 10 & & & 11 & & & 10 & & \\
4 & 7 & & & 14 & & & 13 & & & 15 & & \\
5 & 9 & & & 13 & & & 13 & & & 9 & & \\
6 & 10 & & & 12 & & & 13 & & & 15 & & \\
7 & 11 & & & 10 & & & 10 & & & 8 & & \\
8 & 8 & & & 11 & & & 7 & & & 9 & & \\
9 & 7 & & & 6 & & & & & & & & \\
\hline
\end{tabular}

Fewer design patterns were mentioned during the pre-test by the experimental group $(M=10.44, S D=3.0)$ compared to the control group $(M=13.13, S D=4.45)$. During the post-test, the difference between the experimental $(M=11.33, S D=2.65)$ and control group $(M=11.38, S D=3.34)$ shrank.

The effect size as a difference between the pre-test compared to the post-test is, for the control group $d=-0.476$, $p<0.001$ and for the experimental group $d=0.334, p<0.001$. In both the experimental as the control group there is a difference of limited meaning. Examining the differences in scores in the experimental group and the control group, it can be seen that there is a meaningful difference $(d=0.867, p=0.049)$. This indicates that the experimental group performs substantially better during the post-test compared to the pre-test, whereas this increase is less pronounced for the control group. Thus, the learning gains in the experimental group are significantly greater than those in the control group: there is even a learning loss in the control group.

Additionally, for each educational purpose the number of design patterns the group could come up with was assessed (Table 5). It was decided to differentiate between the total number of mentioned design patters, number of unique design patterns (maximum 6) and the number of design patterns that were mentioned at least five times by the participants.

Table 5. Number of mentioned design patterns - oral observation report, per card

\begin{tabular}{|c|c|c|c|c|c|c|c|c|c|c|c|c|}
\hline \multirow{3}{*}{ Ed. purpose } & \multicolumn{6}{|c|}{ Experimental group } & \multicolumn{6}{|c|}{ Control group } \\
\hline & \multicolumn{3}{|c|}{ Pre-test } & \multicolumn{3}{|c|}{ Post-test } & \multicolumn{3}{|c|}{ Pre-test } & \multicolumn{3}{|c|}{ Post-test } \\
\hline & 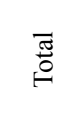 & $\stackrel{\Xi}{\Xi}$ & 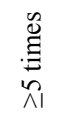 & 氶 & 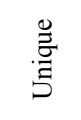 & 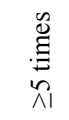 & 丞 & 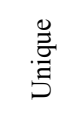 & $\begin{array}{l}\mathscr{U} \\
\stackrel{\Xi}{\Xi} \\
\wedge \\
\wedge 1\end{array}$ & 丞 & : & $\begin{array}{l}\mathscr{\varrho} \\
\stackrel{\Xi}{\Xi} \\
\wedge 1\end{array}$ \\
\hline 1 & 12 & 4 & 1 & 20 & 5 & 3 & 15 & 3 & 2 & 14 & 3 & 1 \\
\hline 2 & 6 & 2 & 0 & 6 & 2 & 0 & 12 & 4 & 1 & 9 & 3 & 0 \\
\hline 3 & 10 & 4 & 1 & 11 & 4 & 1 & 10 & 4 & 1 & 8 & 1 & 1 \\
\hline 4 & 15 & 5 & 2 & 12 & 5 & 1 & 15 & 5 & 1 & 14 & 3 & 1 \\
\hline 5 & 7 & 3 & 0 & 9 & 3 & 0 & 13 & 3 & 1 & 10 & 3 & 1 \\
\hline 6 & 16 & 5 & 2 & 18 & 4 & 2 & 12 & 4 & 1 & 10 & 3 & 1 \\
\hline 7 & 15 & 5 & 0 & 14 & 4 & 1 & 16 & 4 & 3 & 15 & 2 & 2 \\
\hline 8 & 13 & 5 & 1 & 12 & 4 & 1 & 12 & 4 & 0 & 11 & 3 & 1 \\
\hline $\mathrm{M}$ & 11.75 & 4.13 & .88 & 12.75 & 3.88 & 1.13 & 13.13 & 3.88 & 1.25 & 11.38 & 2.63 & 1 \\
\hline $\mathrm{SD}$ & 3.77 & 1.13 & .83 & 4.56 & .99 & .99 & 2.03 & .64 & .89 & 2.62 & .74 & .53 \\
\hline
\end{tabular}

The number of design patterns mentioned by the experimental group (Table 5) is, on average, higher in the 
pre-test $(M=12.75, S D=4.56)$ compared to the post-test $(M=11.75, S D=3.77)$. This contrasts with the control group, which on average mentions less design patterns in the post-test $(M=11.38, S D=2.62)$ compared to the pre-test $(M=13.13, S D=2.03)$. Cohen's effect size value $d=-0.798, p<0.001$ suggests a meaningful negative difference between the pre- and post-test for the control group. Cohen's effect size value $d=0.256, p<0.001$ for the experimental group, which suggests a difference of limited meaning: the experimental group performs better during the post-test compared to the pre-test. The experimental group learned more than the control group did: the control group even displays a meaningful learning loss. The Monte Carlo simulation demonstrates that the chance of these differences in scores being accidental is less than $10 \%(p=0.096)$.

From the post-test sections of Table 5 can be gathered that the experimental group can name more $(\mathrm{M}=3.88$, SD $=0.99)$ unique design patterns than the control group $(\mathrm{M}=2.63, \mathrm{SD}=0.74)$. When the attention is shifted from the total number of design patterns mentioned to the number of unique design patterns, both groups show a decline between the pre-test and the post-test $(\mathrm{p}=0.001)$.

Using the Monte Carlo simulation (10,000 simulations), it was determined that there is a meaningful difference in learning gains of the control group on the one hand, and the experimental group on the other $(d=0.907, p=$ 0.096). This means that it is very likely $(p=0.096)$ that there was a pronounced learning gain in the experimental group, while the control group most likely did not progress at all, and even displays a learning loss.

\subsection{Hypothesis 3: Design Pattern 'Dealing with Disorder'}

To analyze the design pattern 'dealing with disorder', the answers to the questions in the interview were used. The participants in the experimental group have mastered more design patterns on level 2 (beginning) and level 3 (applicable) at the end of the course (Figure 3).

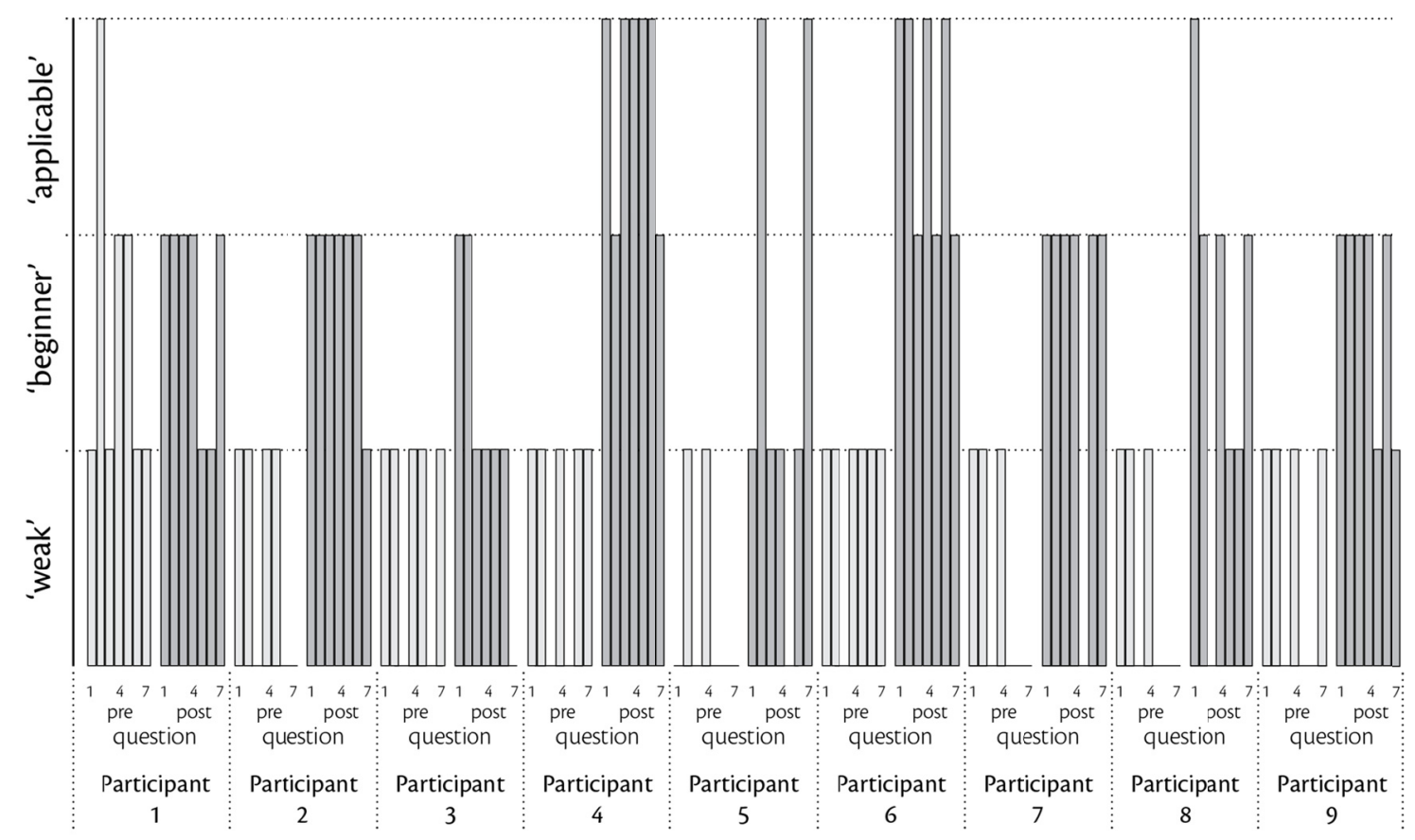

Figure 3. Applicability of the design pattern 'dealing with disorder' as reported in the pre- and post-test interview experimental group

The control group also shows growth, but not as strongly as the experimental group (see Figure 4). 


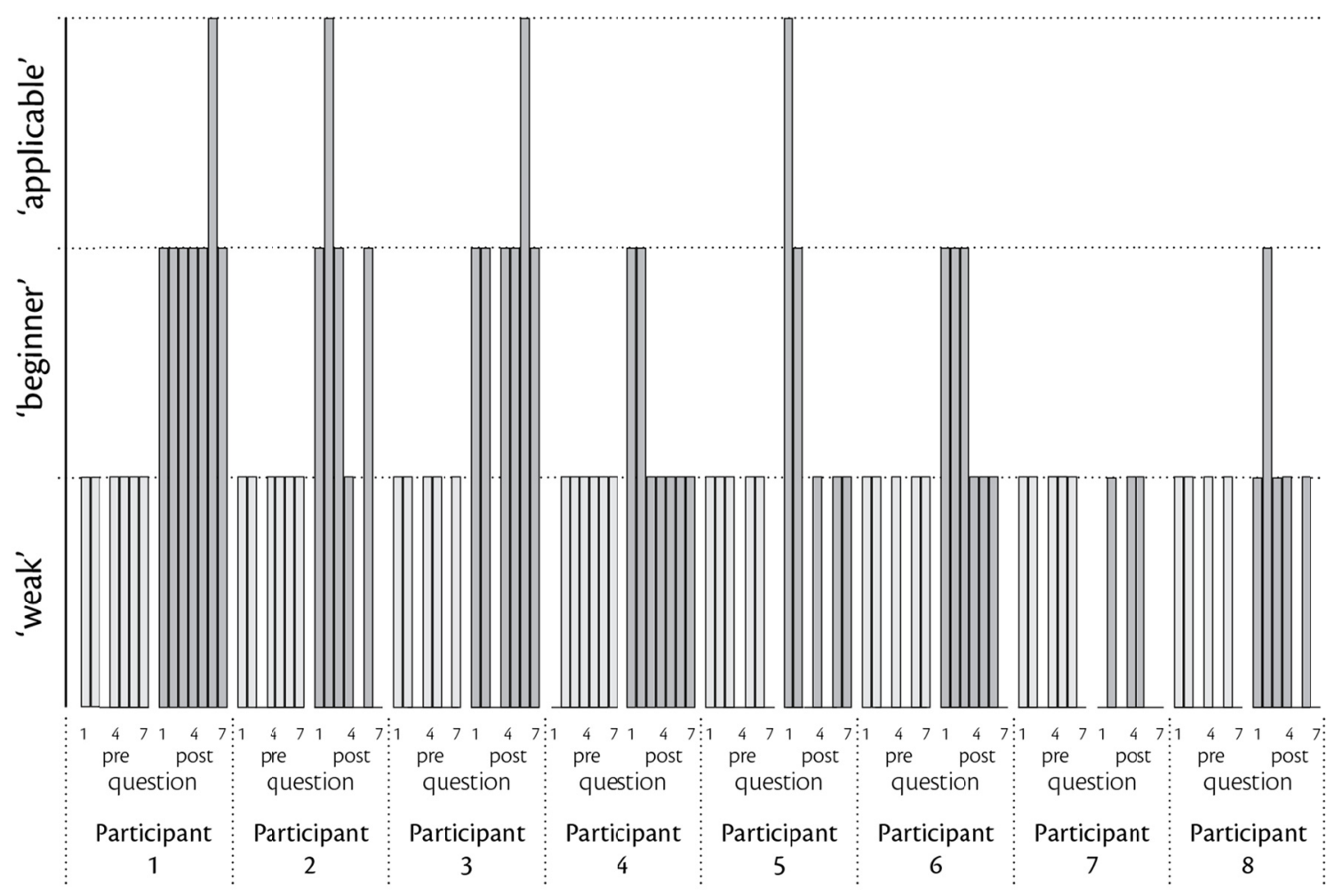

Figure 4. Pre- and posttest results of interview in control group

The difference between the pre-test relative to the post-test is for the control group $d=1.757, \mathrm{p}<0.001$ and for the experimental group $d=3.473, p<0.001)$. The differences are meaningful for both groups, but for experimental group the difference is indeed particularly meaningful. The effect size expressed as a difference between effect sizes in both the experimental and the control group is also meaningful $(d=2.198)$. The empirically determined way the experimental and control group differ in their pre- and post-test results was tested using the Monte Carlo-simulation (10,000 simulations). The results of this simulation show that the probability of this difference occurring by chance is just over $5 \%(p=0.056)$. The experimental group's increase in performance between the pre-test the post-test, is much larger than the control group's increase in performance. This means that the learning gains of the experimental group are larger than the learning gains of the control group.

\section{Conclusions and Discussion}

In this study, three hypotheses were used to test whether the use of video cases in a classroom management course in the second year of the teacher training contributed to the acquisition of situated knowledge in teachers in training.

Using the first hypothesis the amount of educational purposes participants linked to a real-world situation as they viewed it in a video case was investigated. Teachers in training who attended a course that included the use of video cases could link, on average, an equal amount of educational purposes to the video case both before (pre-test) and after (post-test) the course. Teachers in training attending a course that did not use video cases linked fewer of educational purposes to the video case in the post-test compared to the pre-test. Therefore, for both groups, the number of educational purposes that were measured was lower than expected. The observed learning loss in the control group was larger than the one in the experimental group.

The number of elements of the pattern language 'teaching' that teachers in training linked to a video case was investigated using the second hypothesis. Teachers in training who attended a course that included video cases could link more design patterns in the post-test compared to the pre-test. The teachers in training who attended the same course without video cases could also link more design patterns in the post-test, but the difference was less pronounced. Comparing the experimental and the control group's pre- and post-test results allowed that there is a meaningful difference between them to be established. Watching videos thus contributes to the development of the pattern language 'teaching' in teachers in training. 
The third hypothesis was that the design pattern 'Dealing with disorder', would be more developed in teachers in training who had taken a course that used video cases, compared to their fellow students who had taken the same course without video cases. Both groups showed progress of their applicability of this design pattern. For the group who attended the course without video cases this progress was less strong. The data indicates that the development of the design pattern 'Dealing with disorder' is stimulated more by a course that includes video cases compared to one without video.

From the way the first research question was answered, it can be gathered that there was no increase in the number of educational purposes that was linked to case by the experimental group, but that there was a learning loss in the control group. An obvious explanation would be that the results are sound and that the hypothesis can be rejected. But, since the teachers in training who are attending the course are also experiencing their first time being in front of a class, the challenge of thinking about their own process goals while teaching will only start once their internship has begun. Furthermore, the goal of a classroom management course is exclusively focused on classroom management, and pays less attention to educational purposes that do not, or to a lesser extent, deal with classroom management. In addition, it could well be the case that the intervention is to premature, as the intended learning experience can only take shape in the long term. Creating new frameworks for educational purposes will have to have been preceded by a lengthy process of reflection on the teacher in training's own workplace experiences.

Finally, seven out of eight operationalizations of educational purposes were, on average, registered by the measuring instrument used. In future research, the length of the video fragment should accommodate the measuring instrument in such a way that the average number of educational purposes, per respondent, falls in the middle of the scale distribution, so that outliers can be better detected.

Having analyzed the results of hypothesis 2 , it can be seen that both groups feature a pattern language, but the number of elements contained within them is limited. This is the reason the answers are spread out mainly over three out of the six possible elements of the pattern language 'teaching'. The fact that one of these, 'pedagogic action' features prominently, might be explained with the experiences that the participant had as a pupil, which forms the base of their choice of becoming a teacher (Padhy, Emo, Djira, \& Deokar, 2015). It is possible that a teacher in training, who as a pupil witnessed pedagogic successes, but also pedagogic failures in their teachers, formed a wish to do better themselves. It makes sense that 'instruction' and 'dealing with disorder' are frequently mentioned, as they are important parts of the course and because the teachers are immediately confronted with giving instructions and keeping order themselves. In order to teach quality lessons, the teachers need to show improvement in all the elements of the patterns language 'teaching'. A teacher in training who needs to develop on all elements of this pattern language, does not optimally benefit from a course classroom management that is specifically focused on the design pattern 'dealing with disorder'.

The results of hypothesis 3 , regarding the applicability of the design pattern 'dealing with disorder' are the least ambiguous, in the sense that the experimental group does better during the post-test, and this improvement is more pronounced compared with the control group. The most likely reason for this is that the use of video cases contributed to this learning growth. It is important to note that this research involuntarily operationalized situated knowledge in a very specific and narrow way, namely, as knowledge within the context of a video recording. Even the context of authentic video images, cannot replace the full, real, situation in which the situated knowledge is used. One consequence of the situated character of design patterns is the fact that they are not easily transferable (Mor \& Harvey Warburton, 2014). As a result, a teacher in training does not feature a balanced set of design patterns, but is very much still developing one.

In summation, the notable outcome of hypothesis 1 is that there is a learning loss in the control group and an unchanging level of educational purposes in the experimental group. In hypothesis 2 there is a partial learning loss in the control group. It is possible that the decline that was found can be explained as random fluctuation. However, because the Monte Carlo simulation ruled that the chance of that occurring is very small, it could also be possible that the deterioration is not a random fluctuation, but rather that for a number of teachers in training an actual decline in their number of educational purposes and elements of the pattern language 'teaching' occurs. On the one hand, an explanation for this learning loss is that the course that was featured in the research is unilaterally focused on classroom management, which leaves an attention to other educational purposes to be desired. On the other hand, it could mean that in a number of teachers in training there was an actual loss in the number of observed educational purposes and elements of the pattern language 'teaching'. Such a decline is not uncommon when people reflect on issues that were previously obvious to them. In these cases, the realization that not enough thought has been put into the matter leads to doubt (Barden \& Tomala, 2014). A restructuring of knowledge is occurring, and indeed there is a learning experience: the video case they watched gave the 
participants food for thought regarding those aspects of being a teacher, which until then were indisputable to them. Their doubts are demonstrated by the results found, which were measured during a short course. This would mean that learning loss or lack of growth might be explained from the unilateral focus of the course that was used, in addition to the underlying learning experience which can probably only be mapped in the long term.

Because a teacher in training's growth towards becoming an expert is a process that takes time, a suggestion for future research is to investigate the changes in educational purposes and design patterns between students from the second and fourth year of the teacher training. Using these findings, the way a teacher in training thinks about his own actions and the development of his underlying principles and identity can be outlined. Because teacher education seeks to bridge the divides between their students' identity, the theoretical framework the education offers and the classroom their future teachers experience during their internship, understanding the way situated knowledge is accumulated through reflection, supported by video cases, is a priority.

\section{References}

Alexander, C., Ishikawa, S., Silverstein, M., Jacobson, M., Fiksdahl-King, I., \& Angel, S. (1977). A Pattern Language-towns, buildings, construction. New York: Oxford University Press.

Barden, J., \& Tormala, Z. L. (2014). Elaboration and attitude strength: The new meta-cognitive perspective. Social and Personality Psychology Compass, 8(1), 17-29. https://doi.org/10.1111/spc3.12078

Berliner, D. (2001). Learning about and learning from expert teachers. International Journal of Educational Research, 35(5), 463-482. https://doi.org/10.1016/S0883-0355(02)00004-6

Blanton, W. E., Blanton, L. P., \& Cross, L.S. (1994). An exploratory study of how general and special education teachers think and make instructional decisions about special needs students. Teacher Education and Special Education, 17, 62-74. https://doi.org/10.1177/088840649401700107

Blijleven, P. J. (2005). Multimedia-cases: Naar een Brug Tussen Theorie en Praktijk [Multimedia Cases: Toward a Bridge Between Theory and Practice]. Enschede: Universiteit Twente.

Bloom, B. (1984). Taxonomy of Educational Objectives. Boston: Allyn and Bacon.

Borchers, J. O. (2008). A Pattern Approach to Interaction Design. In S. Gill (Ed.), Cognition, Communication and Interaction (pp. 114-131): Springer London. https://doi.org/10.1007/978-1-84628-927-9_7

Borg, S. (2015). Teacher Cognition and Language Education: Research and Practice. London: Bloomsbury Academic.

Boshuizen, H. P. A. (2009). Teaching for expertise: problem-based methods in medicine and other professional domains. In K. A. Ericsson (Ed.), The development of professional performance: Approaches to objective measurement and designed learning environments (pp. 379-404). UK: Cambridge University Press. https://doi.org/10.1017/CBO9780511609817.021

Brophy, J. (1988). Educating Teachers About Managing Classroom and Students. Teaching and Teacher Education, 4(1), 1-18. https://doi.org/10.1016/0742-051X(88)90020-0

Brown, J., Collins, A., \& Duguid, P. (1989). Situated Cognition and the Culture of Learning. Educational Researcher, 18(1), 32-42. https://doi.org/10.3102/0013189X018001032

Carter, K., \& Doyle, W. (1987). Teachers' knowledge structures and comprehension processes. In J. Calderhead (Ed.), Exploring teachers'thinking (pp. 147-160). London: Cassell.

Christofferson, M., \& Sullivan, A. (2015). Preservice Teachers' Classroom Management Training: A Survey of Self-reported Training Experiences, Content Coverage, and Preparedness. Psychology in the Schools, 52(3). https://doi.org/10.1002/pits.21819

Copeland, W. D., \& D'Emidio-Caston, M. (1998). Indicators of development of practical theory in pre-service teacher education students. Teaching and Teacher Education, 14(5), 513-534. https://doi.org/10.1016/S0742-051X(98)00003-1

Copeland, W., Birmingham, C., DeMeulle, L., D’Emidio-Caston, M., \& Natal, D. (1994). Making Meaning in Classrooms: An Investigation of Cognitive Processes in Aspiring Teachers, Experienced Teachers, and Their Peers. American Educational Research Journal, 31(1), 166-196. https://doi.org/10.3102/00028312031001166

Cumming, G. (2014). The new statistics: Why and how. Psychological Science, 25(1), 7-29. https://doi.org/10.1177/0956797613504966 
Derry, J. (2013). Vygotsky philosophy and education (The journal of philosophy of education book series). Hoboken: Wiley. https://doi.org/10.1002/9781118368732

Geerts, W., \& Van Kralingen, R. (2016). Handboek voor leraren. Bussum: Coutinho.

Geerts, W., Van der Werff, A., Hummel, H. G., Steenbeek, H. W., \& Van Geert, P. L. (2015). Assessing situated knowledge in secondary teacher training by using video cases. EAPRIL 2015. Luxembourg City.

Geerts, W., Van Laeken, M., \& Mitzschke, M. (2007). Doorkijk naar Didiclass. Leeuwarden: Noordelijke Hogeschool.

Gibb, R. (2008). Field Coding. Encyclopedia of Survey Research Methods (pp. 277-278). Thousand Oaks, USA: 'SAGE Publications'.

Goodyear, P., Avgeriou, P., Baggetun, R., Bartoluzzi, S., Retalis, S., Ronteltap, F., \& Rusman, E. (2004). Towards a Pattern Language for Networked Learning. In EPRINTS-BOOK-TITLE. Groningen: Johann Bernoulli Institute for Mathematics and Computer Science.

Haider, H., \& Frensch, P. A. (1996). The role of information reduction in skill acquisition. Cognitive Psychology, 30(3), 304-337. https://doi.org/10.1006/cogp.1996.0009

HBO-raad. (2011). Generieke Kennisbasis Tweedegraads lerarenopleidingen. HBO-raad. Retrieved from https://10voordeleraar.nl/documents/kennisbases_bachelor/kb-generiek.pdf

Inspectie van het Onderwijs. (2014). De Sector Lerarenopleidingen in Beeld: Studiesucces, studenttevredenheid en aansluiting op de arbeidsmarkt. Retrieved from https://www.onderwijsinspectie.nl/documenten/publicaties/2014/10/08/de-sector-lerarenopleiding-in-beeld

Jensen, J., MacDaniel, M., Woodard, S., \& Kummer, T. (2014). Teaching to the Test...or Testing to Teach: Exams Requiring Higher Order Thinking Encourage Greater Conceptual Understanding. Educational Psychological Review, 26, 307-329. https://doi.org/10.1007/s10648-013-9248-9

Kim, H. (2011). Exploring freshmen preservice teachers' situated knowledge in reflective reports during case-based activities. The Internet and Higher Education, 14(1), 10-14. https://doi.org/10.1016/j.iheduc.2010.03.005

Kline, R. (2013). Beyond significance testing: Statistics reform in the behavioral sciences (2nd ed.). Washington, D.C.: American Psychological Association. https://doi.org/10.1037/14136-000

Kolfschoten, G., Lukosch, S., Verbraeck, A., Valentin, E., \& de Vreede, G.-J. (2010). Cognitive Learning Efficiency through the Use of Design Patterns in Teaching. Computers \& Education, 54(3), 652-660. https://doi.org/10.1016/j.compedu.2009.09.028

Kounin, J. (1970). Discipline and group management in classrooms. New York, NY: Holt, Rinehart \& Winston.

Kurz, T. L., Llama, G., \& Savenye, W. (2008). Issues and challenges of creating video cases to be used with preservice teachers. TechTrends, 49(4), 67-73. https://doi.org/10.1007/BF02824113

Lam, A. (1997). Embedded Firms, Embedded Knowledge: Problems of Collaboration and Knowledge Transfer in Global Cooperative Ventures. Organization Studies, 18(6), 973-996. https://doi.org/10.1177/017084069701800604

Landau, D., \& Binder, K. (2015). A Guide to Monte Carlo Simulations in Statistical Physics. Cambridge: Cambridge University Press.

Lesgold, A., Greeno, J., Glaser, R., Pellegrino, J., \& Chase, W. (1988). Cognitive and Instructional Factors in the Acquisition and Maintenance of Skill. Pittsburgh: Pittsburgh University Learning, Research and Development Centre.

Masats, D., \& Dooly, M. (2011). Rethinking the use of video in teacher education: A holistic approach. Teaching and Teacher Education, 27(7), 1151-1162. https://doi.org/10.1016/j.tate.2011.04.004

Mor, Y. M., \& Havery Warburton, S. (Ed.). (2014). Practical design patterns for teaching and learning with technology (Trails in education, volume 8). Rotterdam: Sense. https://doi.org/10.1007/978-94-6209-530-4

Padhy, B., Emo, K., Djira, G., \& Deokar, A. (2015). Analyzing Factors Influencing Teaching (pp. 1-12). SAGE Open.

Powell, S., Millwood, R., \& Tindal, I. (2008). Developing technology-enhanced work-focused learning - a Pattern Language approach. Proceedings of Special Track on Technology Support for Self-Organized 
Learners (TSSOL 2008), Salzburg, Austria, 26 May 2008. CEUR Workshop Proceedings, 349, 84-105.

Putnam, R., \& Borko, H. (1999). What Do New Views of Knowledge and Thinking Have to Say About Research on Teacher Learning? Educational Researcher, 29(1), 4-15. https://doi.org/10.3102/0013189X029001004

Rosaen, C. L., Lundeberg, M., Cooper, M., Fritzen, A., \& Terpstra, M. (2008). Noticing Noticing. Journal of Teacher Education, 59(4), 347-360. https://doi.org/10.1177/0022487108322128

Rusman, E., Van Bruggen, J., Cörvers, R., Sloep, P. B., \& Koper, R. (2009). From pattern to practice: evaluation of a design pattern fostering trust in Virtual teams. Computers in Human Behavior, 25(5), 1010-1019. https://doi.org/10.1016/j.chb.2009.01.002

Ruud de Moor Centrum. (2007). Catalogus Casusbank Didiclass. Leeuwarden: Noordelijke Hogeschool.

Sheridan, H., \& Reingold, E. (2011). Recognition memory performance as a function of reported subjective awareness. Consciousness and Cognition, 20(4), 1363-1375. https://doi.org/10.1016/j.concog.2011.05.001

Sherin, M. G., \& Dyer, E. B. (2017). Teacher self-captured video: Learning to see. Phi Delta Kappan, 98(7), 49-54. https://doi.org/10.1177/0031721717702632

Shulman, L. S. (1992). Toward a pedagogy of cases teacher-written cases with commentaries: A teacher-researcher collaboration. In J. Shulman (Ed.), Case methods in teacher education (pp. 1-33). New York: Teachers College Press.

Todman, J. B., \& Dugard, P. (2001). Single-case and small-n experimental designs: A practical guide to randomization tests. Mahwah (NJ): Erlbaum.

van den Bogert, N., Van Bruggen, J., Kostons, D., \& Jochems, W. (2014). First steps into understanding teachers' visual perception of classroom events. Teaching and Teacher Education, 37, 208-216. https://doi.org/10.1016/j.tate.2013.09.001

van Es, E., \& Sherin, M. G. (2002). Learning to notice: Scaffolding new teachers' interpretations of classroom interactions. Journal of Technology and Teacher Education, 10(4), 571-596.

van Meeuwen, L., Jarodzka, H. Brand-Gruwel, S., Kirschner, P. A., de Bock, J. P. R., van Merrienboer, J. J. G. (2014). Identification of effective visual problem solving strategies in a complex visual domain. Learning and Instruction, 32, 10-21. https://doi.org/10.1016/j.learninstruc.2014.01.004

Velon. (2012). Congres voor lerarenopleiders 2012. Vereniging Lerarenopleiders Nederland. Retrieved from http://www.lerarenopleider.nl/velon/congres-voor-lerarenopleiders-2012/

Wolff, C., Jarodzka, H, van den Bogert, N., \& Boshuizen, H. P. A. (2016). Teacher vision: Expert and novice teachers' perception of problematic classroom management scenes. Instructional Science: An International Journal of the Learning Sciences, 44(3), 243-265.

Wolff, C., van den Bogert, N., Jarodzka, H., \& Boshuizen, H. (2015). Keeping an Eye on Learning: Differences Between Expert and Novice Teachers' Representations of Classroom Management Events. Journal of Teacher Education, 66(1), 68-85. https://doi.org/10.1177/0022487114549810

\section{Copyrights}

Copyright for this article is retained by the author(s), with first publication rights granted to the journal.

This is an open-access article distributed under the terms and conditions of the Creative Commons Attribution license (http://creativecommons.org/licenses/by/4.0/). 